\title{
IUGR Does Not Predispose to Necrotizing Enterocolitis or Compromise Postnatal Intestinal Adaptation in Preterm Pigs
}

\author{
LIANQIANG CHE, THOMAS THYMANN, STINE B. BERING, ISABELLE LE HUËROU-LURON, ROMAIN D’INCA, \\ KEYING ZHANG, AND PER T. SANGILD
}

\author{
Institute of Animal Nutrition [L.C., K.Z.], Sichuan Agricultural University, Sichuan, 625014, People's Republic of China; Department of \\ Human Nutrition [L.C., T.T., S.B.B., P.T.S.], University of Copenhagen, Copenhagen DK-1958, Denmark; INRA [I.H.-L., R.D.], UMR \\ 1079 SENAH, Saint-Gilles F-35590, France; Agrocampus Ouest [I.H.-L., R.D.], UMR 1079, SENAH, Rennes F-35000, France
}

\begin{abstract}
IUGR and preterm birth are leading causes of neonatal morbidity. We tested the hypothesis that IUGR predisposes to gut maladaption and necrotizing enterocolitis (NEC) using preterm pigs as models for preterm infants. First, full-term normal birth weight $(\mathrm{NW})$ and IUGR $(\sim 65 \%$ of NW) pigs were compared. IUGR reduced intestinal weight per length, proportion mucosa, villous area, and sucrase activity at $2 \mathrm{~d}$ after birth $(p<0.05)$ but did not change relative organ weights. Next, groups of preterm pigs were fed formula or colostrum, starting at birth or after 2-3 d of total parenteral nutrition (TPN). Neonatal mortality (not related to NEC) was increased in IUGR versus NW preterm pigs (28 vs 10\%, $p<0.01$ ). NEC incidence was similar between IUGR and NW but higher after formula than colostrum feeding (46 vs 12\%, $p<0.01)$ and higher after TPN than without TPN (61 vs 34\% for formula pigs, $p<0.01$ ). After feeding, relative intestinal mass and length were higher in IUGR versus NW pigs $(+25-80 \%, p<0.05)$ while brush border enzyme activities were similar. An enhanced gut trophic response to enteral feeding may help to improve postnatal intestinal adaptation and NEC resistance in preterm IUGR newborns. (Pediatr Res 67: 54-59, 2010)
\end{abstract}

$I_{n}^{\mathrm{L}}$ UGR is associated with higher postnatal morbidity and mortality (1-3). About $8 \%$ of infants in the United States suffer from IUGR (4), and maternal nutrition, genetics, and impaired placental function are factors that may play roles in IUGR etiology. When IUGR appears after birth at full term, the fetus has been exposed to the normal physiologic events prepartum, preparing the fetus for birth. Some of these events may though have been altered in response to IUGR (e.g. increased fetal cortisol levels). IUGR may be associated with adverse effects on organ development and postnatal complications such as respiratory distress syndrome, intraventricular hemorrhage, and long-term handicaps (5-7). When IUGR is combined with preterm birth, the neonate is exposed to the double burden of immature organ function together with IUGR-related changes in organ function and body growth. Optimal nutrition is crucial for these infants, and immature suckling skills and function of the gastrointestinal tract (GIT) often require both parenteral and enteral nutritional support

Received July 13, 2009; accepted September 10, 2009.

Correspondence: Per T. Sangild, Ph.D., D.Sc., Department of Human Nutrition, Faculty of Life Sciences, University of Copenhagen, 30 Rolighedsvej, Copenhagen DK-1958, Denmark; e-mail: psa@life.ku.dk

Supported by the Danish Research Councils, University of Copenhagen, and INRA, France and Sichuan Agricultural University, China.
(8). Regardless, it is unknown whether surviving IUGR preterm neonates differ from normal neonates in their organ and gut responses to nutrition after birth.

Necrotizing enterocolitis (NEC) is a GIT inflammatory disease in which prematurity and enteral feeding are major predisposing factors. Up to $10 \%$ of very low-birth weight preterm infants develop NEC after feeding and mortality is up to $30 \%(9)$. Observational studies indicate that IUGR increases the incidence and severity of feeding-induced NEC development in preterm neonates $(3,10,11)$, but the wide range of gestational ages at delivery, clinical procedures, and varying metabolic complications to IUGR make it difficult to draw conclusions. Hence, little is known about the IUGR-related neonatal response to enteral food.

On the basis of existing observational studies in infants, we hypothesized that IUGR compromises the preterm GIT and its responses to enteral food and thereby lead to increased incidence of NEC. To test this hypothesis, we studied GIT development and NEC incidence in IUGR and normal weight (NW) preterm pigs after $2 \mathrm{~d}$ of enteral feeding with either sow's colostrum or infant formula. Pigs delivered at $\sim 90 \%$ gestation spontaneously develop feeding-induced NEC during the immediate postnatal period (12) and show many other characteristics (13) similar to those of preterm infants born somewhat earlier in gestation. Because total parenteral nutrition (TPN) is a relevant life-saving and growth-promoting clinical intervention in IUGR preterm neonates, we investigated the enteral food responses with or without a preceding 2-3 d period of TPN. For reference, the gut responses to enteral nutrition were first studied in groups of IUGR and normal birth weight newborn pigs born spontaneously at term and suckled by their mother until $2 \mathrm{~d}$ of age.

\section{MATERIALS AND METHODS}

Experiment 1: IUGR and NW pigs born at full term. Pregnant sows (Large White $\times$ Landrace $\times$ Pietrain, experimental herd of INRA, SaintGilles, France) gave birth at full term (115 $\pm 2 \mathrm{~d}$ gestation), and pigs with a birth weight near the mean birth weight $( \pm 0.5 \mathrm{SD})$ were identified as NW, whereas pigs at least 1.5 SD lower birth weight were defined as IUGR.

Abbreviations: ApA, Aminopeptidase A; ApN, Aminopeptidase N; DPP IV, Dipeptidyl peptidase IV; GIT, gastrointestinal tract; IUGR, intrauterine growth restriction; NEC, necrotizing enterocolitis; NW, normal birth-weight; SI, small intestine; TPN, total parenteral nutrition 

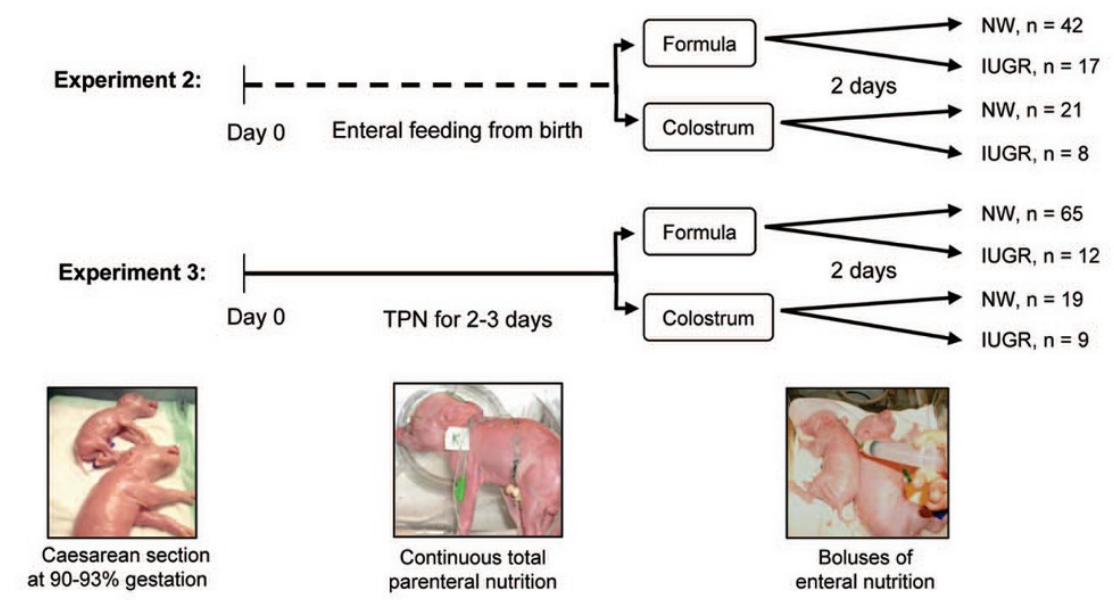

Figure 1. Experimental design for studies on preterm, cesarean-delivered pigs. After birth, pigs were reared in infant incubators with controlled temperature, humidity, and extra oxygen supply and were fed boluses of enteral diets (sow's colostrum or milk formula), either starting from birth (experiment 2) or after a 2-3 period on TPN (experiment 3).
According to these criteria, 12 pairs of pigs (control and IUGR littermates) were randomly selected among the relevant pigs from nine litters. The birth weight range was $1.30-1.48 \mathrm{~kg}$ in the NW group $(n=12)$ and $0.78-1.08 \mathrm{~kg}$ in the IUGR group $(n=12)$. Six pairs of pigs were euthanized (electrical stunning followed by complete exsanguination) before suckling ( $\mathrm{d} 0$ ) and six pairs after $2 \mathrm{~d}$ of suckling. The experiment was conducted in compliance with the guidelines for animal research of the French Ministry of Agriculture.

Experiment 2: IUGR and NW preterm pigs fed enterally immediately after birth. Secondly, we compared GIT development and NEC incidence between preterm IUGR and NW pigs fed enteral nutrition for $2 \mathrm{~d}$, starting within a few hours of birth. Briefly, 271 preterm pigs from 24 sows (Large White $\times$ Landrace) were delivered by cesarean section at $91-93 \%$ gestation (104-106 d). Newborn pigs were categorized as control when the birth weight was within $1 \mathrm{SD}$ unit of the average birth weight of the whole litters and as IUGR when birth weight was at least 1.5 SD lower. On the basis of these selection criteria, 25 pigs were allocated to IUGR (IUGR) and 63 pigs were allocated to NW (NW). While anesthetized, the pigs were prepared with esophageal feeding tubes (6F, Portex, Kent, UK) and fed either sow's colostrum (IUGR-COL, $n=8$; NW-COL, $n=21$ ) or an artificial milk formula (IUGR-FORM, $n=17$; NW-FORM, $n=42)\left(15 \mathrm{~mL} \cdot \mathrm{kg}^{-1} \cdot 3 \mathrm{~h}^{-1}\right)$. Nutrient composition of the sow's colostrum and milk formula (kindly donated by SHS International, Liverpool, UK) is provided elsewhere (14) For passive immunization, maternal plasma was collected at the time of surgery and administered to the pigs ( $20 \mathrm{~mL} \cdot \mathrm{kg}^{-1}$ within $12 \mathrm{~h}$ of birth). All pigs were placed individually in clean infant incubators (Air-Shields, Hartboro, PA) with an environmental temperature of $34-37^{\circ} \mathrm{C}$ and extra oxygen supply (2-3 $\mathrm{L} \cdot \mathrm{min}^{-1}$ ) for $\sim 12 \mathrm{~h}$ postpartum. At $2 \mathrm{~d}$ after birth, the pigs were euthanized for tissue collection. The pigs were sedated with zolazepam and tiletamin $\mathrm{HCl}$ $\left(0.02 \mathrm{~mL} \cdot \mathrm{kg}^{-1}\right.$ body weight, Zoletil, Virbac, France) and then killed with an intracardial injection of sodium pentobarbitone $\left(200 \mathrm{mg} \cdot \mathrm{kg}^{-1}\right)$. A schematic presentation of the experimental design for the preterm pig studies (experiments 2 and 3) is shown in Figure 1.

Experiment 3: IUGR and NW preterm pigs fed enterally after a period of $\boldsymbol{T P N}$. Finally, GIT development and NEC incidence were compared between cesarean-derived NW and IUGR preterm pigs subjected to 2-3 d of TPN before introduction of enteral feeding. Briefly, 164 pigs obtained from 24 sows (Large White $\times$ Landrace) were delivered at $91-93 \%$ gestation as described for experiment 2 . On the basis of the same selection criteria, 21 pigs were identified as preterm IUGR and 84 pigs were identified as preterm NW. The newborn pigs were then fitted with an orogastric tube, and a vascular catheter (4F, Portex, Kent, UK) was placed in the dorsal aorta via the transected umbilical cord. This catheter was used for infusion of TPN, (modified from Nutriflex Lipid plus, Braun, Melsungen, Germany) as described previously (14). TPN was initiated within $6 \mathrm{~h}$ postpartum and was infused continuously via the arterial catheter for $2-3 \mathrm{~d}\left(4 \mathrm{~mL} \cdot \mathrm{kg}^{-1} \cdot \mathrm{h}^{-1}\right.$ for the first $12 \mathrm{~h}$ then increased to $6 \mathrm{~mL} \cdot \mathrm{kg}^{-1} \cdot \mathrm{h}^{-1}$ for the following $24 \mathrm{~h}$ ). Following the TPN period, IUGR and NW were fed either sow's colostrum (IUGR-COL, $n=9$; NW-COL, $n=19$ ) or formula (IUGR-FORM, $n=12$; NW-FORM, $n=65$ ) via the orogastric tube (like in experiment 2) before being killed for tissue collection as above (Fig. 1).

Sample collection and NEC evaluation. The lung, liver, spleen, heart, kidney, adrenal, stomach, small intestine (SI), colon, and pancreas were resected and their wet weights recorded. SI length was measured on an ice-cooled plate and divided into three equal segments designated proximal, middle, and distal SI. One set of samples from these three segments was snap frozen and stored at $-80^{\circ} \mathrm{C}$ for later biochemical analyses. Another set of samples from each intestinal region was opened along its length for measurement of intestinal circumference, wet weight, and percentage of mucosa removed by gentle scraping with a plastic slide. The proportion of mucosa was determined on a dry matter basis after drying both the mucosa and the underling tissue $\left(50^{\circ} \mathrm{C}\right.$ for $\left.72 \mathrm{~h}\right)$. For villous height and crypt depth measurements, the tissues were embedded in paraffin, sectioned $(5 \mu \mathrm{m})$, and stained with eosin and hematoxylin (15). Villous heights and crypt depths were measured from 30 (experiment 1) or 10 (experiments 2 and 3) intact and well-oriented villi using scanned images of several different tissue sections by an image analyzer (Nikon NIS 2.3, USA; experiment 1) or the software SoftWoRx Explorer version 1.1 (Applied Precision, Issaquah, WA; experiments 2 and 3).

The pigs were evaluated for clinical symptoms of intestinal disease every $3 \mathrm{~h}$ (feeding intolerance, stool consistency and color, abdominal distention, and respiratory distress). If severe respiratory distress or abdominal distention was observed, euthanasia and tissue collection was started immediately, before the predetermined end of the experiment at $2 \mathrm{~d}$. At tissue collection, the GIT was evaluated macroscopically for signs of NEC. A NEC scoring system was applied by at least two blinded investigators to characterize the degree of inflammation, edema, hemorrhage, and necrosis in five regions of the gut, leading to the NEC diagnostic criteria described in detail previously (12).

To reliably estimate the NEC incidences, pigs from some additional litters were included $(n=28)$ specifically for calculations of this parameter (without contributing other data). Likewise, for estimating neonatal mortality, we increased the sample size by adding information from some additional preterm pig litters with identical rearing conditions (total $n=525$ for NW; $n=97$ for IUGR).

Brush border enzyme activity. Frozen intestinal mucosa (experiment 1) or whole tissue (experiments 2 and 3) were homogenized and assayed for activity of disaccharidases (lactase, maltase, sucrase) and peptidases (aminopeptidases N [ApN]; aminopeptidase A, [ApA]; dipeptidylpeptidase IV, [DPP IV]), as described earlier (16). The hydrolytic release of one micromol substrate per min at $37^{\circ} \mathrm{C}$ was considered to represent one unit (U) of enzyme activity, expressed per gram of mucosa (experiment 1) or wet intestine (experiments 2 and 3).

Statistics. Results are presented as means \pm SEM. All statistical analyses were based on parametric ANOVA using the MIXED model of SAS (software package version 9.1 SAS Institute, Cary, NC). Weight category (IUGR or NW), time of birth (preterm or term), and diet (colostrum or formula) were included as fixed variables, and litter was included as a random variable. For experiment 1 , the treatment groups consisted of equally balanced paired littermate pigs $(n=6)$. In experiments 2 and 3 , it was important to have group sizes for both IUGR and NW preterm pigs that allowed reliable estimates of the variable NEC incidence across litters. Preterm pigs show greater variability in birth weights than term pigs and all preterm pigs that fitted the birth weight selection criteria were included in the analyses, resulting in bigger group sizes for NW versus IUGR preterm pigs. Difference in NEC incidence between NW and IUGR was evaluated using a $\chi^{2}$ test in SAS, and $p<0.05$ was considered statistically significant.

\section{RESULTS}

Experiment 1: IUGR and NW pigs born at full term. The weight of term IUGR pigs at birth and after $2 \mathrm{~d}$ of suckling 
Table 1. Organ weights and intestinal morphology indices and digestive enzymes in the proximal SI in term IUGR and NW pigs at birth and after 2 of suckling*

\begin{tabular}{|c|c|c|c|c|}
\hline & \multicolumn{2}{|c|}{ Birth } & \multicolumn{2}{|c|}{$2 \mathrm{~d}$ suckling } \\
\hline & $\mathrm{NW}(n=6)$ & IUGR $(n=6)$ & $\mathrm{NW}(n=6)$ & IUGR $(n=6)$ \\
\hline Birth weight $(\mathrm{kg})$ & $1.38 \pm 0.01 \dagger$ & $0.93 \pm 0.02 \ddagger$ & $1.61 \pm 0.02 \S$ & $1.03 \pm 0.03 \dagger \neq$ \\
\hline Lungs $\left(\mathrm{g} \times \mathrm{kg}^{-1} \mathrm{BW}\right)$ & $13.6 \pm 0.8 \ddagger$ & $21.8 \pm 3.7 \dagger$ & $15.8 \pm 0.4 \ddagger$ & $15.9 \pm 0.4 \ddagger$ \\
\hline Liver $\left(\mathrm{g} \times \mathrm{kg}^{-1} \mathrm{BW}\right)$ & $30.0 \pm 2.4$ & $26.6 \pm 2.1$ & $32.1 \pm 1.9$ & $30.6 \pm 2.1$ \\
\hline Pancreas $\left(\mathrm{g} \times \mathrm{kg}^{-1} \mathrm{BW}\right)$ & $0.91 \pm 0.07 \ddagger$ & $0.93 \pm 0.10 \ddagger$ & $1.41 \pm 0.17 \dagger$ & $1.48 \pm 0.18 \dagger$ \\
\hline Kidney $\left(\mathrm{g} \times \mathrm{kg}^{-1} \mathrm{BW}\right)$ & $6.6 \pm 0.3 \ddagger$ & $6.9 \pm 0.5 \neq$ & $8.9 \pm 0.5 \dagger$ & $9.6 \pm 0.5 \dagger$ \\
\hline Stomach $\left(\mathrm{g} \times \mathrm{kg}^{-1} \mathrm{BW}\right)$ & $3.94 \pm 0.12 \ddagger$ & $4.28 \pm 0.26 \ddagger$ & $5.59 \pm 0.29 \dagger$ & $5.34 \pm 0.32 \dagger$ \\
\hline $\mathrm{SI}\left(\mathrm{g} \times \mathrm{kg}^{-1} \mathrm{BW}\right)$ & $24.1 \pm 0.6 \ddagger$ & $24.0 \pm 2.2 \ddagger$ & $37.7 \pm 2.3 \dagger$ & $35.6 \pm 1.0 \dagger$ \\
\hline SI dry matter $(\%)$ & $19.4 \pm 1.5 \dagger$ & $13.9 \pm 1.6 \ddagger$ & $20.1 \pm 0.3 \dagger$ & $19.0 \pm 1.0 \dagger$ \\
\hline SI length $\left(\mathrm{cm} \times \mathrm{kg}^{-1}\right)$ & $274 \pm 7 \ddagger$ & $299 \pm 27 \ddagger$ & $275 \pm 17 \ddagger$ & $356 \pm 10 \dagger$ \\
\hline Mucosa proportion & $0.62 \pm 0.06 \ddagger$ & $0.60 \pm 0.03 \ddagger$ & $0.71 \pm 0.04 \dagger$ & $0.67 \pm 0.05 \dagger$ \\
\hline Villous area $\left(10^{3} \times \mu \mathrm{m}^{2}\right)$ & $26.3 \pm 1.5 \ddagger$ & $26.4 \pm 1.4 \ddagger$ & $58.2 \pm 3.5 \S$ & $40.4 \pm 2.4 \dagger$ \\
\hline Villous height $(\mu \mathrm{m})$ & $400 \pm 18 \ddagger$ & $402 \pm 15$ 蚆 & $687 \pm 26 \S$ & $508 \pm 21 \dagger$ \\
\hline Villous width $(\mu \mathrm{m})$ & $70 \pm 1 \ddagger$ & $70 \pm 1 \neq$ & $92 \pm 2 \dagger$ & $85 \pm 28 \dagger$ \\
\hline Crypt area $\left(10^{3} \times \mu \mathrm{m}^{2}\right)$ & $2.19 \pm 0.05 \ddagger$ & $2.19 \pm 0.06 \$$ & $3.10 \pm 0.07 \dagger$ & $2.81 \pm 0.08 \dagger$ \\
\hline Crypt height $(\mu \mathrm{m})$ & $66 \pm 1 \ddagger$ & $65 \pm 2 \ddagger$ & $78 \pm 2 \dagger$ & $75 \pm 1 \dagger$ \\
\hline Crypt width $(\mu \mathrm{m})$ & $35 \pm 1 \ddagger$ & $35 \pm 1 \neq$ & $43 \pm 1 \dagger$ & $40 \pm 1 \dagger$ \\
\hline Lactase $\left(\mathrm{U} \times \mathrm{g}^{-1}\right.$ mucosa $)$ & $29.6 \pm 3.7$ & $26.5 \pm 4.9$ & $23.7 \pm 3.2$ & $20.5 \pm 3.0$ \\
\hline $\mathrm{ApN}\left(\mathrm{U} \times \mathrm{g}^{-1}\right.$ mucosa $)$ & $6.80 \pm 0.60$ & $7.18 \pm 0.51$ & $8.55 \pm 0.81$ & $7.00 \pm 0.68$ \\
\hline Sucrase $\left(\mathrm{U} \times \mathrm{g}^{-1}\right.$ mucosa $)$ & $0.09 \pm 0.01 \dagger$ & $0.04 \pm 0.01 \ddagger$ & $0.16 \pm 0.02 \S$ & $0.11 \pm 0.01 \dagger$ \\
\hline DPP IV $\left(\mathrm{U} \times \mathrm{g}^{-1}\right.$ mucosa $)$ & $2.11 \pm 0.13$ & $1.75 \pm 0.09$ & $2.27 \pm 0.10$ & $1.73 \pm 0.08$ \\
\hline
\end{tabular}

$*$ Data are mean \pm SEM. Mean values not sharing the same superscript symbol differ significantly $(p<0.05)$.

BW, body weight.

were $\sim 65 \%$ of the weight in term NW pigs (Table $1, p<$ 0.05). Newborn and 2 d-old term IUGR pigs had similar relative weights of all internal organs, except a relatively high lung weight and a low dry weight proportion of the intestine at birth. SI weight increased markedly from birth to $2 \mathrm{~d}$ $(+50 \%, p<0.05)$, and to a similar extent in IUGR and NW pigs. The intestine was relatively long in IUGR pigs, resulting in a reduced wet weight per length of intestine at $2 \mathrm{~d}$ (density 0.10 vs $0.14 \mathrm{~g} \cdot \mathrm{cm}^{-1}, p<0.05$ ) and also lowered villus heights and area in IUGR versus NW term pigs (Table 1). Other morphologic indices and digestive enzyme activities showed no differences related to body weight, except sucrase activity, which was reduced in IUGR pigs $(p<0.05)$. The IUGR effects on all intestinal parameters were similar between the proximal SI (Table 1) and the distal SI (data not shown). No NEC symptoms were observed among term suckling pigs.

Experiment 2: IUGR and NW preterm pigs fed enterally immediately after birth. The body weight of newborn preterm IUGR-FORM and IUGR-COL pigs was $\sim 60 \%$ of that in NW pigs $(p<0.01$, Table 2$)$, and there was no significant body weight gain over the days of the experiment. Neonatal mortality across all litters, before individual pigs started to show NEC symptoms, was $18 \%$, tending to be highest IUGR pigs (24 vs 15\%,p = 0.18). Average rectal temperature during the first $12 \mathrm{~h}$ after delivery was the lowest in IUGR pigs (35.7 \pm 0.3 vs $\left.37.0 \pm 0.3^{\circ} \mathrm{C}, p<0.01\right)$. After $2 \mathrm{~d}$ of formula feeding, 29 and $46 \% \mathrm{NW}$ and IUGR pigs, respectively, $(p=0.2)$ showed the clinical signs of NEC. Together, NEC incidence was higher in formula than colostrum pigs (34 vs 5\%,p< $0.05)$ but also for colostrum pigs, NW and IUGR did not differ (4 and $8 \%, p=0.8$, Table 2).

Both groups of IUGR pigs had higher relative intestinal weight than NW pigs $(+25-30 \%, p<0.05$, Table 2$)$. The SI in IUGR pigs was also longer $(+40-50 \%, p<0.05)$ but with lower SI circumference, resulting in a total SI serosal area (circumference $\times$ SI length/body weight) that was similar between IUGR and NW preterm pigs (data not shown). Apart from the SI, there were limited effects of IUGR on organ weights after enteral feeding for $2 \mathrm{~d}$ after birth (Table 2).

IUGR-FORM pigs had elevated ApA and ApN activities (Fig. 2, $p<0.01$ ), resulting in marked increases in total SI peptidase activities per $\mathrm{kg}$ body weight together with the increase in SI mass $(+50-100 \%, p<0.05$, data not shown). Colostrum feeding significantly increased intestinal dry weight proportion $(+30-40 \%$, Table 2$)$, mucosa proportion, tended to increase villous heights $(+40-45 \%, p<0.1)$, and increased most enzyme activities (except sucrase), compared with formula $(+20-90 \%, p<0.05$, Fig. 2). The diet effects were similar between IUGR and NW pigs.

Experiment 3: IUGR and NW preterm pigs fed enterally after a period of TPN. The birth weight of IUGR pigs fed enterally after TPN was $\sim 60 \%$ of the NW pigs $(p<0.01$, Table 3), and there was no significant body weight gain over the days of the experiment.

Neonatal mortality across all TPN-fed pigs within $24 \mathrm{~h}$ of delivery was $17 \%$, and higher for IUGR than for NW pigs (31 vs $8 \%, p<0.01)$. The NW mortality in TPN pigs tended to be lower than for NW pigs not given a period of TPN before enteral feeding ( $8 v s 15 \%, p=0.15$ ). Again, IUGR and NW pigs showed no significant difference in NEC incidence (Table $3)$. Across the pigs, NEC incidence was higher in experiment 3 than experiment 2 (no TPN period), both for the formula (61 vs 34\%, $p<0.001)$ and colostrum (22 vs 5\%, $p=0.09)$ groups. Across the two experiments, NEC incidence was 46 and $12 \%$ in the formula and colostrum groups, respectively $(p<0.05)$. 
Table 2. Organ weights and intestinal morphology indices in newborn preterm IUGR and NW pigs fed 2 d of enteral formula or colostrum after birth*

\begin{tabular}{|c|c|c|c|c|}
\hline & \multicolumn{2}{|c|}{ Formula-fed pigs } & \multicolumn{2}{|c|}{ Colostrum-fed pigs } \\
\hline & $\mathrm{NW}(n=42)$ & $\operatorname{IUGR}(n=17)$ & $\mathrm{NW}(n=21)$ & IUGR $(n=8)$ \\
\hline Birth weight $(\mathrm{kg})$ & $1.13 \pm 0.02 \dagger$ & $0.70 \pm 0.02 \ddagger$ & $1.15 \pm 0.02 \ddagger$ & $0.70 \pm 0.01 \%$ \\
\hline Kill weight $(\mathrm{kg})$ & $1.10 \pm 0.02 \dagger$ & $0.82 \pm 0.04 \div$ & $1.11 \pm 0.01 \ddagger$ & $0.70 \pm 0.01 \$$ \\
\hline NEC incidence $(\%)$ & $29 \dagger$ & $46 \dagger$ & $4 \ddagger$ & $8 \dagger+$ \\
\hline Adrenal $\left(\mathrm{g} \times \mathrm{kg}^{-1} \mathrm{BW}\right)$ & $0.17 \pm 0.02$ & $0.16 \pm 0.01$ & $0.16 \pm 0.01$ & $0.16 \pm 0.01$ \\
\hline Heart $\left(\mathrm{g} \times \mathrm{kg}^{-1} \mathrm{BW}\right)$ & $7.4 \pm 0.3$ & $7.4 \pm 0.4$ & $7.2 \pm 0.3$ & $7.8 \pm 0.4$ \\
\hline Lung $\left(\mathrm{g} \times \mathrm{kg}^{-1} \mathrm{BW}\right)$ & $20.1 \pm 1.2$ & $20.6 \pm 1.6$ & $21.5 \pm 1.1$ & $18.7 \pm 1.4$ \\
\hline Kidney $\left(\mathrm{g} \times \mathrm{kg}^{-1} \mathrm{BW}\right)$ & $16.0 \pm 1.6$ & $16.6 \pm 1.7$ & $15.2 \pm 1.8$ & $16.6 \pm 1.8$ \\
\hline Spleen $\left(\mathrm{g} \times \mathrm{kg}^{-1} \mathrm{BW}\right)$ & $1.5 \pm 0.1$ & $1.4 \pm 0.1$ & $1.6 \pm 0.1$ & $1.5 \pm 0.1$ \\
\hline Liver $\left(\mathrm{g} \times \mathrm{kg}^{-1} \mathrm{BW}\right)$ & $19.3 \pm 1.9$ & $20.4 \pm 2.2$ & $20.3 \pm 2.1$ & $19.7 \pm 2.2$ \\
\hline Pancreas $\left(\mathrm{g} \times \mathrm{kg}^{-1} \mathrm{BW}\right)$ & $1.28 \pm 0.08$ & $1.39 \pm 0.09$ & $1.34 \pm 0.09$ & $1.26 \pm 0.09$ \\
\hline SI $\left(\mathrm{g} \times \mathrm{kg}^{-1} \mathrm{BW}\right)$ & $30.4 \pm 1.7 \ddagger$ & $37.2 \pm 2.9 \dagger$ & $31.4 \pm 1.9 \dagger$ & $41.4 \pm 3.0 \dagger$ \\
\hline SI dry matter $(\%)$ & $16.1 \pm 0.5 \ddagger$ & $16.0 \pm 0.8 \ddagger$ & $22.4 \pm 1.1 \ddagger$ & $21.0 \pm 1.0 \dagger$ \\
\hline Mucosa proportion & $0.72 \pm 0.02 \ddagger$ & $0.68 \pm 0.02 \div$ & $0.78 \pm 0.02 \ddagger$ & $0.79 \pm 0.03 \dagger$ \\
\hline SI length $\left(\mathrm{cm} \times \mathrm{kg}^{-1}\right)$ & $264 \pm 26 \ddagger$ & $374 \pm 28 \dagger$ & $250 \pm 27 \dagger$ & $367 \pm 29 \dagger$ \\
\hline Villus height $(\mu \mathrm{m})$ & $631 \pm 69$ & $585 \pm 98$ & $879 \pm 122$ & $854 \pm 142$ \\
\hline Crypt depth $(\mu \mathrm{m})$ & $104 \pm 8$ & $112 \pm 9$ & $101 \pm 11$ & $93 \pm 17$ \\
\hline Circumference (mm) & $12.7 \pm 0.5 \S$ & $10.0 \pm 0.7 \ddagger$ & $11.8 \pm 0.6 \dagger$ & $10.5 \pm 0.7 \neq$ \\
\hline
\end{tabular}

Sample size for NEC incidence calculations were $n=12-65$.

* Data are mean \pm SEM. Mean values not sharing the same superscript symbol differ significantly $(p<0.05)$.

BW, body weight.

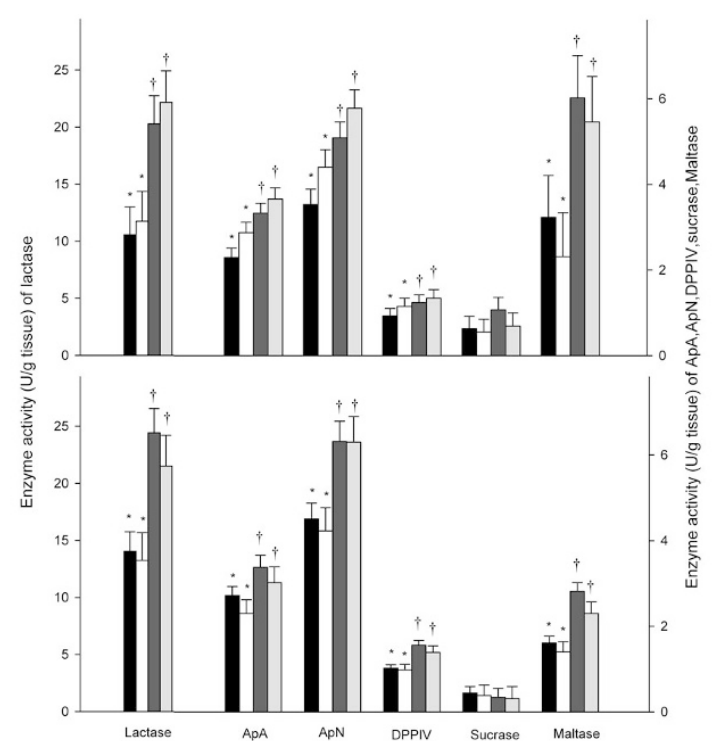

Figure 2. Intestinal enzyme activities in formula-fed NW preterm pigs (black bars), formula-fed intrauterine growth restriction (IUGR) pigs (open bars), colostrum-fed NW pigs (dark gray bars), and colostrum-fed IUGR pigs (light gray bars). The preterm pigs were fed enterally just after birth $(A$, experiment 2) or after a period of TPN ( $B$, experiment 3 ). Bar mean values with different superscript symbols are significantly different $(p<0.05)$.

IUGR pigs had markedly higher SI mass $(+50-80 \%, p<$ $0.01)$, SI length $(+30-40 \%, p<0.05)$, and adrenal gland weights $(+40-50 \%, p<0.05)$ than NW pigs (Table 3$)$. On the other hand, SI serosal circumference and distal intestine villous heights were decreased in IUGR pigs $(-25-30 \%, p<$ 0.05 , Table 3). Relative to formula-fed pigs, colostrum-fed pigs had higher villi $(+30-35 \%, p<0.05)$, but no differences were observed for mucosa or intestinal dry weight proportions. The diet- and IUGR-related differences in SI morphology, and the variable NEC lesions, are illustrated by the representative cross sections of the distal SI shown in Figure 3.
IUGR did not alter tissue-specific enzyme activities relative to NW (Fig. 2) although total SI enzyme activities (per kg body weight) were markedly increased due to increased SI weight $(+25-45 \%$, all $p<0.05$ except sucrase). Across IUGR and NW pigs, colostrum increased all enzyme activities (except sucrase) relative to formula $(+25-70 \%, p<0.05$, Fig. $2)$. Overall, the enzyme values were similar between experiments 2 and 3, except that maltase activity was impaired by a period of TPN before enteral feeding, particularly using colostrum as the enteral feed $(2.96 \pm 0.67$ vs $6.32 \pm 0.83, p<$ 0.01, Fig. 2).

\section{DISCUSSION}

Growth-restricted infants have increased risk of postnatal morbidity and mortality, both short term and long term (3). It is also well documented that undernutrition at critical stages of development produces long-term short stature, organ growth failure, and neuronal and metabolic disturbances (8). Consequently, there is a strong incentive to provide optimal nutrition to IUGR neonates immediately after birth. Although the GIT of IUGR term infants normally tolerate enteral food, albeit at lower quantities, it is not clear whether the double burden of being born preterm and IUGR is associated with additional gut maladaptation. Some studies have reported elevated NEC incidence for IUGR preterm infants $(3,13,17,18)$, but it is not known whether this is due to increased gut sensitivity to enteral feeding or other IUGR-related metabolic complications. Our results indicate that the GIT of IUGR preterm neonates do not have a reduced capacity to tolerate enteral nutrition, as assessed by their intestinal structure, function, and NEC sensitivity.

This study confirms that the first few days of enteral nutrition induce marked intestinal growth $(+50 \%$, experiment 1) and adaptation, supporting earlier studies on term, preterm, 
Table 3. Organ weights and intestinal morphology indices in newborn preterm IUGR and NW pigs fed $2 d$ of total parenteral nutrition $(T P N)$ followed by 2 of enteral formula or colostrum*

\begin{tabular}{|c|c|c|c|c|}
\hline & \multicolumn{2}{|c|}{ Formula-fed pigs } & \multicolumn{2}{|c|}{ Colostrum-fed pigs } \\
\hline & $\mathrm{NW}(n=65)$ & IUGR $(n=12)$ & $\mathrm{NW}(n=19)$ & IUGR $(n=9)$ \\
\hline Birth weight (kg) & $1.11 \pm 0.01 \dagger$ & $0.71 \pm 0.02 \ddagger$ & $1.13 \pm 0.03 \dagger$ & $0.64 \pm 0.05 \ddagger$ \\
\hline Kill weight (kg) & $1.11 \pm 0.02 \dagger$ & $0.70 \pm 0.02 \ddagger$ & $1.18 \pm 0.03 \dagger$ & $0.64 \pm 0.05 \ddagger$ \\
\hline NEC incidence $(\%)$ & $59 \dagger$ & $73 \dagger$ & $12 \ddagger$ & $40 \dagger+$ \\
\hline Adrenal $\left(\mathrm{g} \times \mathrm{kg}^{-1} \mathrm{BW}\right)$ & $0.21 \pm 0.01 \dagger$ & $0.29 \pm 0.03 \S$ & $0.17 \pm 0.01 \ddagger$ & $0.25 \pm 0.02 \dagger \S$ \\
\hline Heart $\left(\mathrm{g} \times \mathrm{kg}^{-1} \mathrm{BW}\right)$ & $7.6 \pm 0.2 \ddagger$ & $8.8 \pm 0.5 \dagger$ & $7.5 \pm 0.3 \ddagger$ & $7.8 \pm 0.5 \ddagger$ \\
\hline Lung $\left(\mathrm{g} \times \mathrm{kg}^{-1} \mathrm{BW}\right)$ & $20.6 \pm 0.7$ & $21.2 \pm 1.5$ & $18.8 \pm 1.1$ & $17.5 \pm 1.8$ \\
\hline Kidney $\left(\mathrm{g} \times \mathrm{kg}^{-1} \mathrm{BW}\right)$ & $9.0 \pm 0.2$ & $10.1 \pm 0.6$ & $8.9 \pm 0.4$ & $9.3 \pm 0.7$ \\
\hline Spleen $\left(\mathrm{g} \times \mathrm{kg}^{-1} \mathrm{BW}\right)$ & $1.84 \pm 0.06$ & $1.83 \pm 0.12$ & $1.75 \pm 0.08$ & $1.80 \pm 0.13$ \\
\hline Liver $\left(\mathrm{g} \times \mathrm{kg}^{-1} \mathrm{BW}\right)$ & $26.9 \pm 1.3$ & $27.6 \pm 1.8$ & $28.6 \pm 1.8$ & $27.0 \pm 2.0$ \\
\hline Pancreas $\left(\mathrm{g} \times \mathrm{kg}^{-1} \mathrm{BW}\right)$ & $1.69 \pm 0.13$ & $1.61 \pm 0.21$ & $1.70 \pm 0.14$ & $1.58 \pm 0.22$ \\
\hline $\mathrm{SI}\left(\mathrm{g} \times \mathrm{kg}^{-1} \mathrm{BW}\right)$ & $29.8 \pm 1.9 \ddagger$ & $54.9 \pm 3.8 \dagger$ & $27.3 \pm 3.0 末$ & $50.8 \pm 4.4 \dagger$ \\
\hline SI dry matter $(\%)$ & $14.8 \pm 0.3$ & $14.8 \pm 0.5$ & $15.8 \pm 0.6$ & $16.1 \pm 0.7$ \\
\hline Mucosa proportion & $0.67 \pm 0.02$ & $0.68 \pm 0.03$ & $0.70 \pm 0.02$ & $0.73 \pm 0.03$ \\
\hline SI length $\left(\mathrm{cm} \times \mathrm{kg}^{-1}\right)$ & $304 \pm 11 \neq$ & $393 \pm 18 \dagger$ & $288 \pm 14.7 \ddagger$ & $404 \pm 20.1 \dagger$ \\
\hline Villus height $(\mu \mathrm{m})$ & $675 \pm 56 \dagger$ & $498 \pm 97 \ddagger$ & $917 \pm 64 \S$ & $637 \pm 91 \dagger$ \\
\hline Crypt depth $(\mu \mathrm{m})$ & $120 \pm 7$ & $102 \pm 11$ & $113 \pm 8$ & $102 \pm 10$ \\
\hline Circumference (mm) & $13.1 \pm 0.4 \dagger$ & $12.7 \pm 0.5 \dagger$ & $12.8 \pm 0.5 \dagger$ & $10.4 \pm 0.7 \ddagger$ \\
\hline
\end{tabular}

Sample size for NEC incidence calculations were $n=10-65$.

$*$ Data are mean \pm SEM. Mean values not sharing the same superscript symbol differ significantly $(p<0.05)$.

BW, body weight.

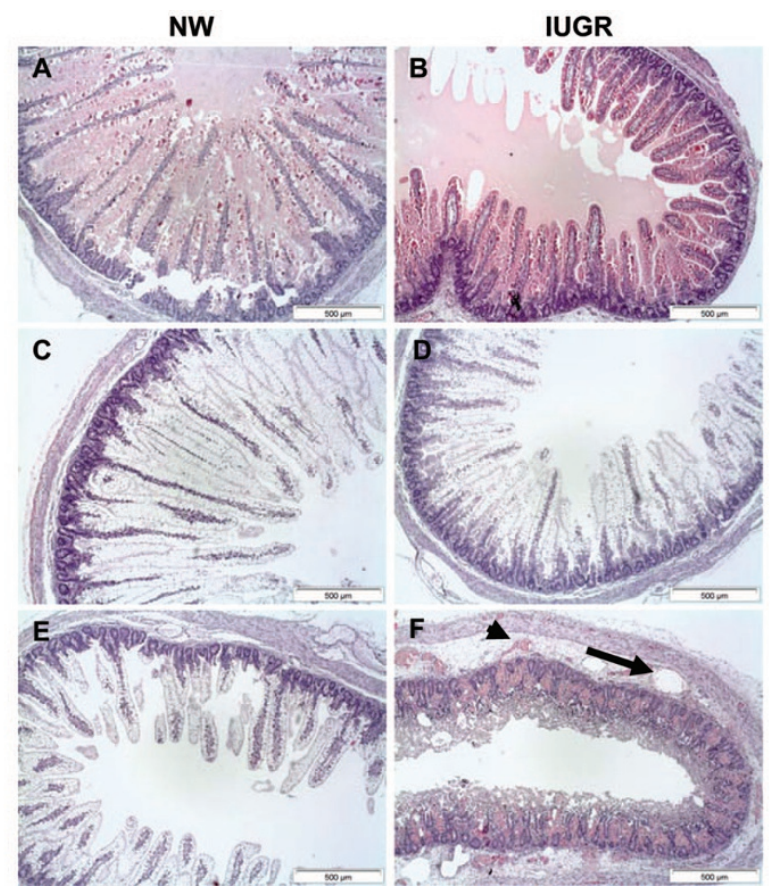

Figure 3. Representative cross sections of the distal SI from pigs in experiment 3. Colostrum-fed healthy pigs $(A, B)$ showed dense staining of endocytosed colostral protein. Villous heights were reduced in IUGR vs NW pigs for both colostrum $(A, B)$ and formula $(C, D)$ pigs. NEC lesions were evident as variable degree of mucosal atrophy and stunted villi ( $E$, formula-fed pig with mild NEC) or as more severe damage with dilated vessels (arrowhead), pneumatosis intestinalis (arrow), and transmural necrosis $(F$, formula-fed pig with severe NEC).

and fetal pigs $(13,19)$. Previous studies in term pigs $(20,21)$ have documented IUGR-related increases in some relative organ weights (lungs, brain) but consistent with data from this study, SI weight, morphology, and mucosal enzyme activities were little affected by IUGR in term pigs. Except for the relative mass and length of the small intestine, few organs differed between IUGR and NW preterm pigs after $2 \mathrm{~d}$ of feeding, and NEC incidences were similar. In fact, our results suggest that preterm IUGR pigs, that survive the immediate neonatal period, may have an enhanced intestinal tropic response to feeding, supporting their higher metabolic needs. One explanation may be that preterm delivery prevents the IUGR neonate from being exposed to the additional stressors of late gestation such as impaired nutrient and oxygen supply and enhanced cortisol secretion.

Without neonatal intensive care (e.g. tube feeding, thermostability, supplemental oxygen), neonatal mortality of normal term pigs is $\sim 10 \%$ but this value is much higher following hypothermia or body weights below $1 \mathrm{~kg}(22,23)$. Neonatal mortality of IUGR preterm pigs was also elevated compared with NW pigs ( $28 v s 10 \%$ across experiments 2 and 3), maybe partly explained by enhanced metabolic demand and hypothermia. The marked gut trophic responses to enteral food introduction in preterm pigs, not only in NW, but even more in IUGR, may help survival in the slightly longer term. Preterm IUGR pigs may possess a relatively high nutrient hydrolytic capacity, resulting mainly from increased relative intestinal weight, rather than increased tissue-specific function. The feeding-induced SI growth response in preterm IUGR pigs was not masked by increases in intestinal water content, as intestinal dry matter proportions were similar between IUGR versus NW pigs.

Feeding the preterm IUGR neonate remains a big challenge and both parenteral and enteral nutrition support are often required to achieve reasonable growth rates. However, it remains unclear whether enteral feeding for preterm IUGR infants should be initiated immediately after birth or delayed with some days of TPN to let the neonate reach a degree of hemodynamic and metabolic stability before introduction of enteral food (24). In our study, the overall organ growth and SI responses were similar with and without TPN, except that 
the feeding-induced increase in relative intestinal mass in IUGR pigs, relative to NW pigs, was highest in pigs subjected to a few days of TPN $(+50-80 \% v s+25-30 \%)$. On the other hand, villous heights were reduced in IUGR pigs only after TPN. Although TPN may help the immediate postnatal survival of NW preterm neonates, TPN did not improve immediate neonatal survival of preterm IUGR pigs or their resistance against later feeding-induced NEC. Although TPN may improve metabolic stability, it could also induce inappropriate bacterial colonization and lacking luminal factors to stimulate antimicrobial and immunologic defense mechanisms (13). Markedly reduced maltase activity in TPN pigs may be a sign that TPN renders the mucosa more susceptible to a diet- and colonization-dependent dysfunction and inflammation $(18,19,25)$.

Although it is clear that mother's milk is beneficial for the immature intestine, relative to infant formula, it is less clear when and in what quantities enteral nutrition should be introduced to optimize body growth and GIT health (8). We showed that IUGR preterm pigs mounted a marked tropic and enzymatic response to sow's colostrum when supplied shortly after birth or after a period of TPN. In agreement with earlier observations in NW pigs (14), formula consistently decreased tissue-specific enzyme activities, and increased NEC sensitivity in both NW and IUGR preterm pigs, relative to colostrum. A high NEC-sensitivity was associated with degrees of intestinal edema as indicated by the low intestinal dry weight proportions in formula- and colostrum-fed pigs with TPN and in formula-fed pigs without TPN. Only colostrum-fed preterm pigs without TPN showed minimal NEC lesions and had intestinal dry weight proportions that were similar to values in normal term 2 d-old pigs.

In conclusion, IUGR does not predispose to NEC in preterm pigs and the SI shows a high degree of feeding-induced gut growth, compared with NW preterm pigs. If preterm IUGR neonates can survive the initial postnatal period using intensive clinical support, these neonates could have a relatively high capacity to adapt to enteral food introduction, despite their growth-retarded body condition. Nevertheless, it remains a challenge to determine the optimal feeding mode, diet, and amount of nutrients (minimal enteral feeding procedures) that will induce metabolic stability and GIT maturation and also to protect the sensitive IUGR preterm neonate against feedinginduced gut inflammatory disorders.

\section{REFERENCES}

1. Regev RH, Lusky A, Dolfin T, Litmanovitz I, Arnon S, Reichman B 2003 Excess mortality and morbidity among small-for-gestational-age premature infants: a population-based study. J Pediatr 143:186-191
2. Garite TJ, Clark R, Thorp JA 2004 Intrauterine growth restriction increases morbidity and mortality among premature neonates. Am J Obstet Gynecol 191:481-487

3. Gilbert WM, Danielsen B 2003 Pregnancy outcomes associated with intrauterine growth restriction. Am J Obstet Gynecol 188:1596-1601

4. Martin JA, Kung HC, Mathews TJ, Hoyert DL, Strobino DM, Guyer B, Sutton SR 2008 Annual summary of vital statistics: 2006. Pediatrics 121:788-801

5. McIntire DD, Bloom SL, Casey BM, Leveno KJ 1999 Birth weight in relation to morbidity and mortality among newborn infants. N Engl J Med 340:1234-1238

6. Schulzke SM, Deshpande GC, Patole SK 2007 Neurodevelopmental outcomes of very low-birth-weight infants with necrotizing enterocolitis: a systematic review of observational studies. Arch Pediatr Adolesc Med 161:583-590

7. Eichenwald EC, Stark AR 2008 Management and outcomes of very low birth weight. N Engl J Med 358:1700-1711

8. Hay WW Jr 2008 Strategies for feeding the preterm infant. Neonatology 94:245-254

9. Moss RL, Dimmitt RA, Henry MC, Geraghty N, Efron B 2001 A meta-analysis of peritoneal drainage versus laparotomy for perforated necrotizing enterocolitis. J Pediatr Surg 36:1210-1213

10. Bernstein IM, Horbar JD, Badger GJ, Ohlsson A, Golan A 2000 Morbidity and mortality among very-low-birth-weight neonates with intrauterine growth restriction. The Vermont Oxford Network. Am J Obstet Gynecol 182:198-206

11. Manogura AC, Turan O, Kush ML, Berg C, Bhide A, Turan S, Moyano D, Bower S, Nicolaides KH, Galan HL, Muller T, Thilaganathan B, Gembruch U, Harman CR, Baschat AA 2008 Predictors of necrotizing enterocolitis in preterm growth-restricted neonates. Am J Obstet Gynecol 198:638.e1-e5

12. Sangild PT, Siggers RH, Schmidt M, Elnif J, Bjornvad CR, Thymann T, Grondahl ML, Hansen AK, Jensen SK, Boye M, Moelbak L, Buddington RK, Westrøm BR, Holst JJ, Burrin DG 2006 Diet- and colonization-dependent intestinal dysfunction predisposes to necrotizing enterocolitis in preterm pigs. Gastroenterology 130:17761792

13. Simchen MJ, Beiner ME, Strauss-Liviathan N, Dulitzky M, Kuint J, Mashiach S, Schiff E 2000 Neonatal outcome in growth-restricted versus appropriately grown preterm infants. Am J Perinatol 17:187-192

14. Bjornvad CR, Thymann T, Deutz NE, Burrin DG, Jensen SK, Jensen BB, Molbak L, Boye M, Larsson LI, Schmidt M, Michaelsen KF, Sangild PT 2008 Enteral feeding induces diet-dependent mucosal dysfunction, bacterial proliferation, and necrotizing enterocolitis in preterm pigs on parenteral nutrition. Am J Physiol Gastrointest Liver Physiol 295:G1092-G1103

15. Sangild PT, Petersen YM, Schmidt M, Elnif J, Petersen TK, Buddington RK, Greisen G, Michaelsen KF, Burrin DG 2002 Preterm birth affects the intestinal response to parenteral and enteral nutrition in newborn pigs. J Nutr 132:2673-2681

16. Marion J, Petersen YM, Rome V, Thomas F, Sangild PT, Le Dividich J, Le Huërou-Luron I 2005 Early weaning stimulates intestinal brush border enzyme activities in piglets, mainly at the posttranscriptional level. J Pediatr Gastroenterol Nutr 41:401-410

17. Aucott SW, Donohue PK, Northington FJ 2004 Increased morbidity in severe early intrauterine growth restriction. J Perinatol 24:435-440

18. Kudsk KA 2002 Current aspects of mucosal immunology and its influence by nutrition. Am J Surg 183:390-398

19. Wildhaber BE, Yang H, Spencer AU, Drongowski RA, Teitelbaum DH 2005 Lack of enteral nutrition-effects on the intestinal immune system. J Surg Res 123:8-16

20. Wang T, Huo YJ, Shi F, Xu RJ, Hutz RJ 2005 Effects of intrauterine growth retardation on development of the gastrointestinal tract in neonatal pigs. Biol Neonate 88:66-72

21. Xu RJ, Mellor DJ, Birtles MJ, Reynolds GW, Simpson HV 1994 Impact of intrauterine growth retardation on the gastrointestinal tract and the pancreas in newborn pigs. J Pediatr Gastroenterol Nutr 18:231-240

22. Tuchscherer M, Puppe B, Tuchscherer A, Tiemann U 2000 Early identification of neonates at risk: traits of newborn piglets with respect to survival. Theriogenology $54: 371-388$

23. van Rens BT, de Koning G, Bergsma R, van der Lende T 2005 Preweaning piglet mortality in relation to placental efficiency. J Anim Sci 83:144-151

24. Bombell S, McGuire W 2008 Delayed introduction of progressive enteral feeds to prevent necrotising enterocolitis in very low birth weight infants. Cochrane Database Syst Rev CD001970

25. Nakasaki H, Mitomi T, Tajima T, Ohnishi N, Fujii K 1998 Gut bacterial translocation during total parenteral nutrition in experimental rats and its countermeasure. Am J Surg 175:38-43 